\title{
Lumbosacral Lipoma
}

National Cancer Institute

\section{Source}

National Cancer Institute. Lumbosacral Lipoma. NCI Thesaurus. Code C6500.

A benign well-circumscribed tumor, composed of lobules of mature adipocytes, that arises within the lumbosacral tissue of the spine. 